\title{
A Scale to Assess Science Activity Videos (SASAV): The Study of Validity and Reliability
}

\author{
Yilmaz Kara ${ }^{1}$, Hasan Bakirci ${ }^{2}$ \\ ${ }^{1}$ Faculty of Education, Bartin University, Bartin, Turkey \\ ${ }^{2}$ Faculty of Education, Yuzunci Yil University, Van, Turkey \\ Correspondence: Yilmaz Kara, Faculty of Education, Bartin University, Bartin, Turkey.
}

Received: November 21, 2017

Accepted: December 11, 2017 Online Published: December 12, 2017

doi:10.11114/jets.v6i1.2861

URL: https://doi.org/10.11114/jets.v6i1.2861

\begin{abstract}
The purpose of the study was to develop an assessment scale for science activity videos that can be used to determine qualified science activity videos that can fulfill the objectives of activity based science education, help teachers to evaluate any science activity videos and decide whether to include into science learning process. The subjects for the study comprised a group of 47 science teacher candidates who were at their junior year in state university. In scope of a must course, each science teacher candidates were assigned an objective from K12 science curricula. Then, they were expected to seek for a science activity that can be conducted and recorded in form of 3-5 minutes long science activity video. The teacher candidates were asked to evaluate science activity videos developed by themselves for their classes, schools, and individual use through a scale to assess science activity videos. Science teacher candidates were given three weeks to complete the evaluation form, after which time they were returned to the researchers for assessment. The data from the scale were analyzed through descriptive and item analysis in terms of frequency, reliability and factor routines. The body of the scale covers 20 evaluation criteria in four major categories as technical features, narrator features, activity process, and security issues. The developed evaluation scale for science activity videos will provide a useful logical framework to help educators and/or trainers to identify adequate science activities in point of quality for their instructional purposes.
\end{abstract}

Keywords: educational technology, science education, teacher education, assessment and measurement

\section{Introduction}

The one of the descriptions of science is the effort of humanity to recognize nature and to deal with nature for the sake of humanity (McComas, 2017). At the beginning learning the living things, the rules of the nature and its functioning was necessary for the survival struggle, learning the science has become a necessity to live a healthy and high-quality life in our ages (Slough \& Chamblee, 2017). The necessity to learn science by all of the people who are the part of society and to use science in order to facilitate life has led to the development of science education. The influence of educational theories has formed science education into activity-based understanding which aimed to make students become science literate individuals from the educational understanding purposing to transfer information in a specific systematic order (Zeidler \& Abd-El Khalick, 2017).

Activity-based instruction derives from philosophies based on the view that learning occurs in the mind of the individual (Renner \& Marek, 1990). The individual tries to understand the nature through previously occurred learning experiences. The learner actively structures the encountered concepts in the mind during the learning experiences. In other words, a learner should have learning experiences in order to make learning come true. Science education, which is about humanity, the environment and the mystery of nature, has the potential to offer learners different learning experiences (Hobbs, 2015). Many objects and events can be subjected into the science activities such as living things from the microscopic worlds of single-celled organisms to the giant ocean whales, the matter and its components from the particle fragments of matter to the energy particles, the inner structure of matter from simple elements to complex organic compounds. The leading inventions for the technology and the biographies of their inventors can turn into inspiring science activities for students. The formation of technological practices through the science knowledge and the engineering behind the products can be carried into the science classes (Amin, 2011; Wu, Hwang, \& Tsai, 2013). Despite the high potential to offer learning experiences for the learners that science has, science teachers often have 
difficulty in bringing science teaching activities to the educational process.

It is necessary to introduce effective science learning activities in order for science teachers and science teacher candidates to adopt science activities that will provide effective learning experiences to learners and to be included in learning processes (Luft, Bang \& Hewson, 2016). First of all, teachers tend to teach science subjects as they are taught to them. For this reason, it is difficult for the teachers who are not learned the science subjects through the activity-based science education to implement activity-based science education into the science classes. In-service training courses, workshops or seminars are organized on a limited basis to enable teachers to improve themselves in activity-based science education, attendance, accommodation costs, and often do not match work schedule of teachers. The most of the in-service and professional development efforts carried out by overcoming the difficulties about participation and attendance are considered by teachers as having the already known content, theory-weighted, impossible to implement in science education and so waste of time. In educational institutions where behavioral learning approach is dominant, it is also not possible for young teachers to get help from their experienced colleagues about activity-based science teaching (Åhman, Gunnarsson \& Edfors, 2015). Teachers who want to bring effective science activities to their classes have difficulties in reaching ready-to-use science activities (Harris \& Roenman, 2017). Teachers need to have easy access to the effective science activities, have an idea about their functioning, and make a decision to include them in their science classes.

Despite the difficulties involved in the involvement of effective science teaching activities in science teaching processes, teachers have the tendency to implement activity-based science teaching in their classrooms in case providing ready to implement activity-based science teaching materials (Kim, Hyun \& Shin, 2015). The science activities that increase student achievement, affect motivation positively and contribute to the development of positive attitudes of students are adopted and started to be used by the science teacher. The science teaching activities where students are reluctant to participate, lack of teaching aspect and get negative reactions are considered as unqualified science activities and are abandoned (Ogan-Bekiroglu, 2007).

Today, progress in technology and the increase in the given respect to the education make it inevitable to take advantage of technological opportunities in solving educational problems (Moemeke, 2014). The computers and connection possibilities among computers can allow to interact quickly with individuals, store and process a large number of information in variety of formats and enable to use with other media tools to display a wide range of audiovisual input streams (Pereira, Barros, Rezende Filho \& Fauth, 2012). Cameras have become widely used since they are capable of making audiovisual records, and even everyone has owned integrated cameras with the smartphones (Twum, 2017). Moreover, it is possible to store recorded audio images by transferring them to the computer environment and editing by adding sound, image and writing effects to them through video processing programs. Also, the internet allows the prepared videos to be displayed at any time and in an unlimited number of times through devices that are open to access (Francisco, 2017; Ostrosky, Mouzourou, Danner \& Zaghlawan, 2013). Briefly, it is possible to record the applications of the effective science activities in audiovisual formats, to make arrangements on them and to watch an unlimited number of times from everywhere with internet access (Jin, Johnson, Shin \& Anderson, 2017).

The science activity videos are the recorded and edited science activities in video format. The science activity videos can be recorded even with simple mobile phone cameras. In addition, the recorded science activity videos can be edited through movie maker software programs. The prepared science activity videos are able to guide science teachers about the science activity which is going to be implemented in science learning process. In this way, the science teacher become more experienced about the science activity (Coffey, 2014; Martin \& Siry, 2012). The science activity videos also can be helpful for the use in activity implementation process. The science students can watch the science activity before the implementation. Instead of written constructions, science activity videos provide audio-visual presentation of the science activity (Gaudin et al., 2014). The science students can get more experience about the science activity through watching the video as an example and learn more about stages of science activity. In brief, the science activity videos have the potential to provide experience to teachers and science students about the science activity if they included enough quality to use in science learning procedures.

Despite the facilities provided by technology, there are a limited number of platforms for science teachers providing access to the effective science learning activities (Johnson \& Cotterman, 2015). There is no platform including science activity practices to cover the entire science curriculum. The platforms such as video search engines allows to perform name-based searches and the information since the entered by the uploader during upload process often does not subject to any controls. The information about the video can be limited, away from educational purpose, not reflecting reality or useless (Lichter, 2012). An easy-to-use measuring tool is needed that can help to distinguish effective science activity videos from any other science activity videos. Thus, it was aimed to develop an assessment scale for science activity videos that can be used to determine qualified science activity videos that can fulfill the objectives of activity based science education, help teachers to evaluate any science activity videos and decide whether to include into science learning process. 
Rather than concentrating on peer assessments of prospective science teachers, we focused on development of a scale to assess science activity videos in this manuscript. The development procedure of the scale is going to be explained including the setting for the assessment. At last, the validity and reliability of the developed scale will be discussed in terms of findings.

\subsection{Theoretical Framework}

The studies about the science activities and video assessment was examined in order to construct necessary theoretical framework for the development of the scale (Arya et al., 2014; Coffey, 2014; van Es et al., 2014). The studies on video analysis are mostly included the critics of the learning process in terms of pedagogical knowledge and science content knowledge (Tripp \& Rich, 2012; Wiens et al., 2013). In addition, technical features of the video files considered for the use of science activity videos in science learning processes (Calandra \& Rich, 2014). The videos need to have convenient image and sound quality for the learning. Also, the recording should be performed in true shooting angle in order to display the main procedure or core action of science activity. The movie should be long enough to exhibit all science activity without decreasing the attention of science learners. The movie file also can be arranged in use of learning settings through using video editing programs (Blomberg et al., 2013; Danielowich, 2014). In terms of pedagogical knowledge, the previous research papers are emphasized that the teacher should plan and conduct the learning process in appropriate time (Christ, Arya \& Chiu, 2014). The experienced teachers use appropriate voice to communicate with the learners. The speech of the teacher should be supported by mimics. The studies also indicate that students are affected by the appearance of the teacher (Gaudin et al., 2014; Martin \& Siry, 2012). In the same vein, the previous researches about science activities revealed that a science activity should address to the objective of the science curriculum. Then the success of the science activity mostly depends on true implementation of the procedure. The science activity can have the potential to enable science learning even if the required materials are ready to use and stages of the activity followed truly. The science students are going to reach to the findings if they follow the instructions but that does not guarantee the science learning. The findings should be interpreted in order to prove the learning is realized in an expected way (Erdmann \& March, 2014). In the researches on science activities, the safety issues are also underlined to consider the safety issues, warnings, and waste removal procedures (Mattias \& Mats, 2014).

\section{Method}

\subsection{Research Design}

In this study, the survey design was used since the aim of the study was determining the characteristics that could be used in the process of selecting and evaluating effective science activity videos. An assessment form has been developed in order to realize the purpose of study in this context and attempts have been made to determine the opinions of science teacher candidates. In order to fulfill the aim of the study, the studies were examined and interpreted about the characteristics of quality science activities and a form was developed to be used in determining the educational characteristics of science activity videos through considering the expert opinion. As a result of the research, scale was developed to assess science activity videos through considering the opinions of science teacher candidates.

\subsection{Participants}

The study group of the study were 47 science teacher candidates (\%63 female) who enrolled in an undergraduate level must course called as "laboratory practices in science education". The participant teacher candidates were at their junior year at the faculty of education. The participants were completed the courses which provide knowledge and skills that can be used for this study such as Principles and Methods of Teaching, Computer, Educational Technologies and Material Design, and Measurement and Assessment. The science teacher candidates prepared the science activity videos and completed the on-line evaluation scale for the science activity videos on the VideoLab web site. In addition, participants were required to complete Online Peer Assessment Self Efficacy Survey (OPASS) in order to examine whether they have self-efficacy to make peer assessment for science activity videos (Tseng \& Tsai, 2010). The average score of each participant on the OPASS were higher than the required level to make online peer assessment. So, the participants had the required self-efficiency to make peer assessment for science activity videos.

\subsection{Limitations of the Study}

The assessment of the science activity videos to be evaluated within the scope of the study was limited in science teacher candidates from a state university and the science activity videos developed by them through considering the design of the internet environment for the evaluation, the time, the software, the hardware, the necessity of providing face-to-face information about the subject and the science activity videos to the developers and the time requirements for the development of science activity videos. 


\subsection{Assumptions}

The science teacher candidates are supposed to respond sincerely to the questions in the scale by examining the science activity videos.

\subsection{Data Collection and Setting}

The set of criteria stated in theoretical framework of the study were used to determine the educational features that should be included in the science activity videos and the formation of the theoretical part (Gaudin et al., 2014; van Es et al., 2014; Wiens et al., 2013). The list of the characteristics that should be included in quality science activity videos was prepared during the development of the scale. It has been tried to make the items of the scale for the qualified science activity videos to be appropriate for the purpose of the research and not to be understood differently. For this, it is ensured that the items in the properties list do not consist of long and complicated expressions. It has also been noted that each item in the list of the scale is expressed in a measurable manner and describe only one feature of the quality science activity videos. After formation of the items, the list was introduced to the experts in the field of science education and educational technology. The experts were required to question whether the specified items are represents the qualities that should be included in the science activity videos that are sufficient in terms of educational manner. So, the items of the assessment scale of the science activity videos to be applied to the teacher candidates were obtained after the expert opinions, some of the items in the scale were corrected in the direction of the suggestions and some items were removed from the scale. In line with the aim of the study, a Likert-type assessment instrument consisting of a total of 23 items on a scale of five equal intervals was prepared and the final form was given to the scale for the assessment of science activity videos.

The science teacher candidates were required to develop short scale science activity videos in scope of an undergraduate level must course named as "laboratory practices in science education". In scope of the course, each science teacher candidates were assigned an objective from K12 science curricula. Then, they were expected to seek for a science activity that can be conducted and recorded in form of 3-5 minutes long science activity video. For this, science teacher candidates need to consider appropriate science activities, activity instructions, and video recording. After identifying their science activities, each of the science teacher candidates was required to fill out science activity information form. The provided information on this form was used on the VideoLab web site to inform about the science activity (http://videolab.sead.com.tr). Then teacher candidates were expected to record their 3 to 5 -minute-long science activity videos. They were enabled to use laboratory opportunities of the faculty. They were encouraged to design and implement different ideas about to science activity. After recording the videos, they were able to add text, visual or sound effects and optimize technical features of the video since the science teacher candidates had computer courses at undergraduate level and they were able to use movie-maker programs. Finally, the videos need to be uploaded for publication on on-line web site.

Before the assessment the purpose and scope of the study was explained to the science teacher candidates. The use of the assessment form for the evaluation of the science activity videos was shown on an example. For teacher candidates, a three-week period has been given to complete the assessment forms. During the assessment, teacher candidates are required to follow the following steps;

- Review the brief information in order to have a clear idea about the purpose and feature of science activity videos.

- Fill in the section about the general information on the evaluation form.

- Watch uninterruptedly the science activity video from the beginning to the end.

- Watch the video with a critical eye from a science student perspective.

- Fill in the Scale to Assess Science Activity Videos (Wait while the video is filled in, so you can apply for it if needed).

- Follow each step separately for all of the videos and fill in one assessment form for each video on the web site.

The form was completed by 47 science teacher candidates. The teacher candidates were reassured that their responds on the scale and the results of this research would not be used for any purpose other than this study.

\subsection{Data Analysis}

The data was analyzed after completion of the assessment scale by the participants. All of the collected data was loaded into SPSS 22.0 package program and used for statistical analysis. Frequency, correlation, Cronbach alpha reliability test and factor analysis statistical techniques were used in the analysis of the data.

\section{Results}

\subsection{Measure of Sample Adequecy}

The Kaiser-Meyer-Olkin Measure of Sampling Adequacy (KMO) value reports the amount of covariance created by the 
variables. The fact that the $\mathrm{KMO}$ value is close to 1.00 that indicates the data are suitable for factor analysis while the $\mathrm{KMO}$ value is below the 0.50 reports that is not right to perform factor analysis with this data. The Bartlett test value and its significance test whether the variables correlate with each other. It can be said that it is not appropriate to perform factor analysis with this data if the obtained $\mathrm{p}$ value is 0,10 or more (McMillan \& Schumacher, 2014).

When we look at the value of KMO in our study, it is seen that this value $(0,939>0,50)$ is over 0,50 . This value can be considered as "pretty good" in terms of KMO decision scale and shows that the sample size is sufficient to process statistical analysis. The Barlett test value was found to be 25806,459 and $p$ value was 0,000 . According to this, the result of the Bartlett test is significant at the level of 0.001 and it can be said that the factor analysis is appropriate for the correlation matrix (Table 1).

Table 1. The results of KMO and Barlett test

\begin{tabular}{llc}
\hline & Approx. Chi Square & 25806,459 \\
Barlett's test of Sphericity & $\mathrm{df}$ & 190 \\
& Sig. (p) & 0,000 \\
\hline KMO Measure & & 0,939 \\
\hline
\end{tabular}

\subsection{Validity Studies}

The validity of the scale was tested in two different ways as content and structure validity.

\subsubsection{Content Validity}

Expert opinion has been referred in the study of content validity. The experts were the faculty members who had at least doctoral degree in the field of science education and computer assisted learning. The experts were required to review the items of the scale to assess science activity videos in terms of content validity. After their review, the experts suggested that the scale as a whole can be used to determine the adequacy of the science activity videos.

\subsubsection{Structure Validity}

Table 2. The result of factor structure for the scale to assess science activity videos

\begin{tabular}{lc}
\hline Items & Factor loading \\
\hline Technical features & 0.806 \\
The movie file has the appropriate image quality. & 0.804 \\
The movie is recorded by the correct shooting angle. & 0.690 \\
The movie file has the appropriate sound quality. & 0.745 \\
Movie effects are used to support voice narration. & 0.795 \\
Expository text effects are used at necessary frames. & 0.622 \\
Narrator features & 0.514 \\
The narrator briefly introduced himself. & 0.576 \\
The narrator used a clear sound. & 0.600 \\
The narrator used the appropriate costume for the content. & 0.707 \\
The narrator has supported his speech with appropriate gestures, mimics or movements. & \\
The narrator completed the experiment within a reasonable time. &
\end{tabular}

\section{Activity process}

Introductory information is included about the experiment.

0.737

The order on the instruction was followed during the experiment.

0.729

The materials were correctly introduced before the experiment.

0.800

The experimental processes have been accurately displayed.

0.817

The experimental process is truly narrated.

0.821

The findings are clearly underlined at the end of experiment.

0.762

The findings are interpreted to elicit the results

0.764

\section{Safety issues}

The experiment was conducted in consideration of necessary safety precautions. 0.626

$\begin{array}{ll}\text { The necessary warnings have been taken to take the safety precautions. } & 0.897\end{array}$

The removal process is stated for waste material formed during the experiment. 0.869

In order to determine the structure validity of the scale, the items of the scale to assess science activity videos were subject to Principal Component Analysis. The items of the scale were collected under four factors with the eigen value above one. In order to reach as independent factors as possible from each other, factor analysis was continued using varimax with Kaiser normalization. Analyzes were carried out with 20 items with factor loadings of less than 0.30 and multiple factorial entries with factor load differences of 0.10 or less. As a result of repeated rotations, it was observed that the items in the scale were gathered under four factors, five in the two, seven in one, and three in the last factor. Factors are named as technical features, narrator features, activity process and security issues through taking into 
account the item contents. The load values of the items in the first factor are between 0.690 and 0.806 , the load values of the items in the second factor are between 0.514 and 0.707 , the load values of the items in the third factor are between 0.729 and 0.821 , and the load values of the items in the fourth factor are between 0.626 and 0.897 . Four factors together account for $65.741 \%$ of the total variance. The contribution of the first factor to the variance was determined as $30.921 \%$, the contribution of the second factor to the variance was $13.927 \%$, the contribution of the third factor to the variance was $10.605 \%$ and the contribution of the fourth factor to the variance was $10.288 \%$. The factor analysis results of the items (factor loadings of the items) are given in Table 2.

The correlation values were calculated for the scores from the scale to assess science activity videos and subscale scores. The correlation value between "technical features" and "narrator features" is 0.674 , the correlation value between "activity process" and "technical features" is 0.601 , the correlation value between "activity process" and "narrator features" is 0.754 , the correlation value between "security issues" and " technical features" is 0.349 , the correlation value between "security issues" and "narrator features" is 0.334 , and the correlation value between "security issues" and "activity process" is 0.260 . It was seen that the correlation between narrator features subscale. When the correlations of the sub-dimensions with the total scores were calculated, the correlation of the technical features was 0.842 , the correlation of the narrative features was 0.879 , the correlation of the activity process was 0.859 and the correlation of the security issues was 0.564 with the scale to assess science activity videos (Table 3 ). In this context, it can be said that the scale to assess the science activity videos is able to evaluate the features of science activity videos in terms of the correlation scores. The high correlations of the subscales with the total score indicate that the subscales are represents the dimensions that should be found in the effective science activity videos.

Table 3. Correlation matrix for the scale to assess science activity videos and subscales

\begin{tabular}{lcccc}
\hline & Technical features & Narrator features & Activity process & Safety issues \\
\hline Technical features & - & & & \\
Narrator features & $0.674^{*}$ & - & - & - \\
Experimental process & $0.601^{*}$ & $0.754^{*}$ & $0.260^{*}$ & $0.334^{*}$ \\
Safety issues & $0.349^{*}$ & $0.879^{*}$ & $0.859^{*}$ & $0.564^{*}$ \\
SASAV & $0.842^{*}$ & & & \\
\hline
\end{tabular}

* $\mathrm{p}<0.01$

\subsection{Reliability Studies}

Reliability of the scale was obtained by calculating Cronbach alpha values. The calculated Cronbach alpha value for the overall scale to assess the science activity videos was found to be 0.912 , while the Cronbach alpha values for the subscales were 0.804 for the technical features, 0.755 for the narrative features, 0.921 for the activity process and 0.773 for the safety issues (Table 4). It is seen that the reliability coefficients obtained for both the subscales and the whole of the scale are higher than the minimum reliability value $(\mathrm{p}=0.7)$. These reliability values show that the scale to assess science activity videos has the reliability that can be used in this research.

Table 4. Cronbach alpha reliability coefficient for the scale to assess science activity videos and subscales

\begin{tabular}{lcccc}
\hline & Number of Items & Mean & Standard Deviation & Reliability Coefficient \\
\hline Technical features & 5 & 4.083 & 3.683 & 0.804 \\
Narrator features & 5 & 4.226 & 3.125 & 0.755 \\
Experimental process & 7 & 4.257 & 4.130 & 0.921 \\
Safety issues & 3 & 3.486 & 2.790 & 0.773 \\
SASAV & 20 & 4.090 & 10.973 & 0.912 \\
\hline
\end{tabular}

The quartile values of the scale to assess science activity videos was calculated based on the values obtained from the science teacher candidates. The Q1 value of the scale is 77, the Q2 value is 81, and the Q3 value is 89, so that the scale can be used in other studies after validity and reliability studies. According to this calculation, the average scores of science activity videos between 20-77 are meaningless, the average scores of science activity videos between 78-80 are unacceptable in terms of quality, the average score of science activity videos between 81-88 is weak and that the average scores of the science activity videos between 89-100 are sufficient videos in terms of quality.

\section{Conclusion}

In this study, the scale to assess science activity videos was developed within the theoretical framework established by previous studies. The scale consists of four analytically distinct subscales with high reliability and validity values. The subscales are technical features, narrator features, activity process and security issues (Danielowich, 2014; Erdmann \& March, 2014; Martin \& Siry, 2012; Tripp \& Rich, 2012). The final version of the scale can be implemented in the form of a five-point Likert type scale consisting of 20 items. The technical features and narrator features five, the activity process seven, and the security issues consist of three items. All of the items were written with the positive verbal 
structure. The responses to the items of the scale are rated as "absolutely disagree", "disagree", "undecided", "agree" and "strongly agree".

The respond of "absolutely disagree" scored as 1 point while the respond of "strongly agree" scored as 5 points. The given responds to the items of the subscales can be summarized as technical features score, narrator features score, activity process score and security issue score. At the same time, the responds given all over the scale can be evaluated as the total score summing up the whole of the evaluation. A responder can have at least 5 and maximum 25 points on the technical features and narrator features subscales, at least 7 and maximum to 35 points from the activity process subscale, and at least 3 and maximum 15 points from the security subscale. The lowest score that can be taken from the scale is 20 points while the highest score is 100 points.

The correlations were calculated between the sum of each subscale and the sum of the scale to test the validity of the scale, and all results were found to be statistically significant. This result can be interpreted as the scale has the required structure validity.

In the analysis of the researches to be carried out with the scale to assess science activity videos, the total score obtained from the scale can be used as a continuous variable. Also, the obtained scores from the scale can be used to categorize science activity videos as (a) the meaningless to use, (b) unacceptable in terms of quality, (c) weak in terms of quality, and (d) sufficient in terms of quality through considering the quarterly value calculations.

Although the aim of the study is to develop a form for the assessment of science activity videos that will enable teachers to evaluate more effectively the science activity videos they can use in their classrooms, schools and as individuals, the developed assessment form can also be used by those who are interested about science activity videos. It is expected that the scale to assess science activity videos will be used by educators and researchers.

In conclusion, this study focused on constructing comprehensive criteria for selecting and evaluating the science activity videos required for effective and controversial discussion on the assessment of science activity videos. The gathered criteria to assess science activity videos provide a useful logical framework that can help educators and instructors to select quality science activity videos in terms of quality for their educational purposes. However, it should not be forgotten that there are no agreed standards or criteria for evaluating science activity videos (Calandra \& Rich, 2014; van Es et al., 2014). For this, there is a high level of need to develop guideline standards for science activities that will assist in distinguishing qualified science activities from others on order to provide criteria for the team members who are involved in the development process because of their specific field expertise such as instructional designer, programmer, subject area expert and assessment expert, evaluators, and users.

\section{References}

Åhman, N., Gunnarsson, G., \& Edfors, I. (2015). In-service science teacher professional development. NorDiNa: Nordic Studies in Science Education, 11(2), 207-219. https://doi.org/10.5617/nordina.2048

Amin, J. (2011). Development and implementation of an activity based science teaching programme for pre-service student teachers, ProQuest Dissertations and Theses.

Arya, P., Christ, T., \& Chiu, M. M. (2014). Facilitation and teacher behaviors: an analysis of literacy teachers' video-case discussions. Journal of Teacher Education, 65(2), 111-127. https://doi.org/10.1177/0022487113511644

Blomberg, G., Renkl, A., Sherin, M. G., Borko, H., \& Seidel, T. (2013). Five research based heuristics for using video in pre-service teacher education. Journal for Educational Research Online, 5(1), 90-114.

Calandra, B., \& Rich, P. J. (Eds.). (2014). Digital video for teacher education: Research and practice. NY: Routledge

Christ, T., Arya, P., \& Chiu, M. M. (2014). Teachers' reports of learning and application to pedagogy based on engagement in collaborative peer video analysis. Teaching Education, 25(4), 349-374. https://doi.org/10.1080/10476210.2014.920001

Coffey, A. M. (2014). Using video to develop skills in reflection in teacher education students. Australian Journal of Teacher Education, 39(9), 86-97. https://doi.org/10.14221/ajte.2014v39n9.7

Danielowich, R. M. (2014). Shifting the reflective focus: encouraging student teacher learning in video-framed and peer-sharing contexts. Teachers and Teaching: Theory and Practice, 20(3), 264-288. https://doi.org/10.1080/13540602.2013.848522

Erdmann, M. A., \& March, J. L. (2014). Video reports as a novel alternate assessment in the undergraduate chemistry laboratory. Chemistry Education Research and Practice, 15(4), 650-657. https://doi.org/10.1039/C4RP00107A

Francisco Jr., W. E. (2017). Digital Videos of Experiments Produced by Students: Learning Possibilities. In: Hahl K., Juuti K., Lampiselkä J., Uitto A., Lavonen J. (eds) Cognitive and Affective Aspects in Science Education Research. 
Contributions from Science Education Research, 3, Springer, Cham. https://doi.org/10.1007/978-3-319-58685-4_11

Gaudin, C., Flandin, S., Ria, L., \& Chalies, S. (2014). An exploratory study of the influence of video viewing on preservice teachers' teaching activity: normative versus developmental approaches. Form@ re, 14(2), 21-50.

Harris, E., \& Roenman, A. (2017). Discussing science in professional learning communities: Teachers collaborate to transform next generation science teaching and learning. Science and Children, 55(1), 53-57. https://doi.org/10.2505/4/sc17_055_01_53

Hobbs, L. (2015). Play-Based Science Learning Activities. Science Communication, 37(3), 405-414. https://doi.org/10.1177/1075547015574017

Jin, H., Johnson, M., Shin, H., \& Anderson, C. (2017). Promoting student progressions in science classrooms: A video study. Journal of Research in Science Teaching, 54(7), 852-883. https://doi.org/10.1002/tea.21388

Johnson, H. J., \& Cotterman, M. E. (2015). Developing Preservice Teachers' Knowledge of Science Teaching through Video Clubs. Journal of Science Teacher Education, 26(4), 393-417. https://doi.org/10.1007/s10972-015-9429-0

Kim, J., Hyun, D., \& Shin, A. (2015). Development and application of inquiry activity-based science teaching and learning materials utilizing traditional games. Journal of Educational Research Institute, 17(2), 1. https://doi.org/10.15564/jeri.2015.11.17.2.1

Lichter, J. (2012). Using YouTube as a platform for teaching and learning solubility rules. Journal of Chemical Education, 89(9), 1133-1137. https://doi.org/10.1021/ed200531j

Luft, J., Bang, E., \& Hewson, P. (2016). Help yourself, help your students: What research says about choosing a good professional development program. The Science Teacher, 83(1), 49-53. https://doi.org/10.2505/4/tst16_083_01_49

Martin, S., \& Siry, C. (2012). Using video in science teacher education: an analysis of the utilization of video-based media by teacher educators and researchers. In B. Fraser, K. Tobin, \& C. Campbell (Eds.), Second international handbook of science teaching and learning (pp. 417e433). The Netherlands: Springer. https://doi.org/10.1007/978-1-4020-9041-7_29

Mattias, L., \& Mats, L. (2014). Negotiating the relevance of laboratory work: Safety, procedures and accuracy brought to the fore in science education. Nordina: Nordic Studies in Science Education, 10(1), 32-45. https://doi.org/10.5617/nordina.638

McComas, W. F. (2017). Understanding How Science Works: The Nature of Science as The Foundation for Science Teaching and Learning. School Science Review, 98(365), 71-76.

McMillan, J., \& Schumacher, S. (2014). Research in education: Evidence-based inquiry. (Seventh edition; International ed.).

Moemeke, C. D. (2014). Can integrating media into science learning activities improve students' learning outcomes? American Journal of Educational Research, 2(3), 138-141. https://doi.org/10.12691/education-2-3-4

Ogan-Bekiroglu, F. (2007). Bridging the Gap: Needs Assessment of Science Teacher In-Service Education in Turkey and the Effects of Teacher and School Demographics. Journal of Education for Teaching: International Research and Pedagogy, 33(4), 441-456.

Ostrosky, M. M., Mouzourou, C., Danner, N., \& Zaghlawan, H. Y. (2013). Improving teacher practices using microteaching: planful video recording and constructive feedback. Young Exceptional Children, 16(1), 16-29. https://doi.org/10.1177/1096250612459186

Pereira, M. V., Barros, S. S., Rezende Filho, L. A. C., \& Fauth, L. H. A. (2012). Audiovisual physics reports: Students' video production as a strategy for the didactic laboratory. Physics Education, 47(1), 44-51. https://doi.org/10.1088/0031-9120/47/1/44

Renner, J. W., \& Marek, E. A. (1990). An Educational Theory Base for Science Teaching. Journal of Research in Science Teaching, 27(3), 241-246. https://doi.org/10.1002/tea.3660270307

Slough, S., \& Chamblee, G. (2017). 21st Century Pedagogical Content Knowledge and Science Teaching and Learning. Journal of Computers in Mathematics and Science Teaching, 36(2), 173-187.

Tripp, T., \& Rich, P. (2012). Using video to analyze one's own teaching. British Journal of Educational Technology, 43(4), 678-704. https://doi.org/10.1111/j.1467-8535.2011.01234.x

Tseng, S. C., \& Tsai, C. C. (2010). Taiwan college students' self-efficacy and motivation of learning in online peer assessment environments. Internet and Higher Education, 13, 164-169. 
https://doi.org/10.1016/j.iheduc.2010.01.001

Twum, R. (2017). Utilization of Smartphones in Science Teaching and Learning in Selected Universities in Ghana. Journal of Education and Practice, 8(7), 216-228.

van Es, E. A., Tunney, J., Goldsmith, L. T., \& Seago, N. (2014). A framework for the facilitation of teachers' analysis of video. Journal of Teacher Education, 65(4), 340-356. https://doi.org/10.1177/0022487114534266

Wiens, P. D., Hessberg, K., LoCasale-Crouch, J., \& DeCoster, J. (2013). Using a standardized video-based assessment in a university teacher education program to examine preservice teachers' knowledge related to effective teaching. Teaching and Teacher Education, 33(1), 24-33. https://doi.org/10.1016/j.tate.2013.01.010

Wu, P. H., Hwang, G. J., \& Tsai, W. H. (2013). An expert system-based context-aware ubiquitous learning approach for conducting science learning activities. Educational Technology \& Society, 16(4), 217-230.

Zeidler, D., \& Abd-El Khalick, F. (2017). Science education research thrives in an open, global community. Journal of Research in Science Teaching, 54(4), 437-438. https://doi.org/10.1002/tea.21393

\section{Copyrights}

Copyright for this article is retained by the author(s), with first publication rights granted to the journal.

This is an open-access article distributed under the terms and conditions of the Creative Commons Attribution license which permits unrestricted use, distribution, and reproduction in any medium, provided the original work is properly cited. 